\title{
DINÂMICAS DE INOVAÇÃO: ANÁLISE DAS ESTRATÉGIAS DE INOVAÇÃO NO CLUSTER DE MANGA DA RIDE
}

\author{
Ailton Abel Rodrigues Santos* \\ Felipe Araújo Ferreira* \\ Jéfferson Jesus de Araújo* \\ Deranor Gomes de Oliveira** \\ Valdner Daízio Ramos Clementino***
}

RESUMO: O artigo tem como objetivo estudar as dinâmicas de inovação nas empresas exportadoras de manga da Região Integrada de Desenvolvimento Econômico, localizada no semiárido nordestino, observando como as ações estratégicas de inovação contribuíram para a formação e formulação de estratégias competitivas diferenciadas. Propõe-se, para isso, um framework para analisar as ações estratégicas de inovação, ante os desafios impostos pela intensificação da competição no mercado internacional da manga. Esta pesquisa tem como base empírica os dados recolhidos de um conjunto de empresas exportadoras de manga. O presente trabalho tem um caráter qualitativo-exploratório e utiliza, como referência, um framework do modelo integrado de inovação. Os dados foram recolhidos por meio de pesquisa documental e por questionários aplicados aos principais gestores das empresas. As inovações ocorreram em um continuum e vão desde a adoção de novos produtos/ serviços a melhorias significativas nos processos de produção, caracterizadas por estratégias de inovações tecnológicas de comportamento incremental, fatores estes que têm contribuído para a manutenção e a sustentabilidade das vantagens competitivas das empresas frente à intensificação da competitividade no mercado nacional e internacional.

PALAVRAS-CHAVE: Agronegócio; Diferenciação; Inovação; Modelo Integrado; RIDE.

Graduando em Engenharia de Produção pela Universidade Federal do Vale do São Francisco (UNIVASF). Brasil.

** Mestre em Psicologia pela Universidade Federal do Espírito Santo (UFES), Docente do Colegiado de Administração da Universidade Federal do Vale do São Francisco (UNIVASF), Brasil.

*** Doutor em Gestão, com especialização em ciências econômicas e processo decisório, pela Universidade de Évora - Portugal; Docente Assistente IV da Universidade Federal do Vale do São Francisco (UNIVASF), Brasil; E-mail: valdner.ramos@univasf.edu.br 


\section{INNOVATION DYNAMICS: ANALYSIS OF MANGO INNOVATION STRATEGIES BY RIDE}

ABSTRACT: Innovation dynamics of mango export firms of the Integrated Region for Economic Development (RIDE) in the semi-arid region of northeastern Brazil are analyzed. Strategic innovation activities have contributed towards the formation and elaboration of differentiated competitive strategies. A framework has been suggested to investigate innovation strategic activities in the wake of intense competition on the mango international market. Current qualitative and exploratory research is foregrounded on data from a group of mango export firms and employs an innovation integrated model framework. Data were collected through documental research and interviews by the firms' managers. The continuum innovations range between the adoption of new products/services and significant improvement in the production process characterized by technological innovation strategies related to behavior. In fact, these factors have contributed towards the maintenance and sustainability of the firms' competitiveness in the wake of intensification of competitiveness on the national and international markets.

KEY WORDS: Agribusiness; Differentiation; Innovation; Integrated Model; RIDE.

\section{INTRODUÇÃO}

A inserção da temática da inovação na agenda da pesquisa e da produção de diversos setores econômicos reflete a demanda de uma sociedade cada vez mais fundamentada no conhecimento. Esse novo contexto tem gerado um novo ambiente organizacional e transacional, transformando, significativamente, as relações no mundo empresarial, cenário esse também observado no agronegócio brasileiro, em que as empresas procuram, da mesma forma que em outros setores, superar as suas restrições e os seus obstáculos por meio da adoção de inovações.

Nessa perspectiva, a discussão e o enquadramento dessa temática no contexto do agronegócio tornam-se imperativos, uma vez que somente após a compreensão desse fenômeno será possível transpor os desafios agora impostos às empresas pela sociedade do conhecimento. Entende-se que os avanços e as transformações tecnológicas, promovidas pelo processo de inovação, contribuíram para as mudanças profundas e estruturais do meio envolvente das empresas 
(FREEMAN; SOETE, 2008).

A questão norteadora deste trabalho consiste na realização de um estudo sobre as dinâmicas de inovação, especificamente observando como as ações estratégicas de inovação contribuíram para a formação e formulação de estratégias competitivas diferenciadas nas empresas exportadoras de manga da Região Integrada de Desenvolvimento Econômico (RIDE), localizada no semiárido nordestino.

A RIDE é composta por municípios de dois Estados: Pernambuco (Lagoa Grande, Orocó, Petrolina e Santa Maria da Boa Vista) e Bahia (Casa Nova, Curaçá, Juazeiro e Sobradinho). A dinâmica econômica é oriunda, principalmente, da fruticultura irrigada, devido à posição estratégica da região, banhada pelas águas do rio São Francisco, o que lhe confere um grande potencial de desenvolvimento da agricultura irrigada (RIBEIRO, 2014). A participação da RIDE na produção de manga, no âmbito nacional e dos Estados membros, torna a região o principal polo produtor de manga do país. Tais fatores demonstram a importância da temática e o foco do estudo. Na condução do estudo, recorreu-se a um modelo de pesquisa inovador, por sua aplicação no setor agrícola, cujo objetivo é o de diagnosticar a capacidade de inovação e os possíveis desfasamentos/desempenho entre as empresas atuantes nesse setor, selecionando-se, aleatoriamente, um conjunto de seis (06) empresas exportadoras de manga atuantes na RIDE. Metodologicamente, trata-se de um estudo exploratório-descritivo, com levantamento de dados documentais e estatísticos visando à caracterização da principal região exportadora de manga do Brasil. Além disso, foram levantados dados primários, mediante questionários aplicados aos gestores das empresas envolvidas. Por fim, realizou-se uma revisão de um conjunto de publicações das teorias de inovação, objetivando o desenvolvimento de uma melhor compreensão da temática proposta.

O artigo é constituído de cinco seções, com seu conteúdo distribuído pelas seguintes seções: Introdução; Fundamentação teórica; Aspectos metodológicos; Análise e discussão dos resultados; e Considerações finais e limitações do trabalho.

\section{FUNDAMENTAÇÃO TEÓRICA}

Na década de 1960, quando foi elaborado o Manual Frascati, por iniciativa da Organização para Cooperação e Desenvolvimento Econômico (OCDE), 
desenvolveram-se grandes esforços de coletas de estatísticas sobre o processo de inovação tecnológica. O manual permitiu a criação de conceitos e definições sobre as atividades de pesquisa e desenvolvimento (P\&D), assim como possibilitou a criação de um sistema de indicadores do esforço e desempenho tecnológicos.

Diante desse cenário, compreender o processo de inovação como fenômeno econômico e de diferencial competitivo passou a ser uma condição e, ao mesmo tempo, uma ação que já contempla os objetivos de parte dos gestores na atualidade. Contudo ainda persiste uma ausência de práticas capazes de criar uma cultura de inovação nas organizações, bem como uma lacuna entre a necessidade e a capacidade de inovar (RAMOS, 2015).

Nas circunstâncias atuais, face a um ambiente em constantes mutações, a pressão competitiva do mercado global exige que a nova empresa seja competitiva ao ponto de conseguir diferenças em forma de vantagens competitivas, a partir de inovações em vários níveis, ou seja, no produto, no processo de produção ou na gestão das empresas, criando novas oportunidades de negócios e estruturas organizacionais mais eficientes e eficazes.

\subsection{DEFINIÇÕES E TIPOLOGIAS}

\subsubsection{Definições}

A primeira distinção a ser feita, inicialmente, é entre técnica e tecnologia. A tecnologia pode ser entendida como o conhecimento sobre determinada técnica, enquanto que a técnica envolve a aplicação desse conhecimento. Outra distinção importante que se deve destacar é entre invenção e inovação. A invenção se refere à criação de um processo, técnica ou produto inédito; já a inovação ocorre com a efetiva aplicação na prática de uma invenção e de sua aceitação pelo mercado. Assim, pode-se dizer que não há inovação sem invenção, assim como não há técnica sem tecnologia (TIGRE, 2006). Lustosa (2011) destaca que o processo de inovação corresponde a todas as atividades que geram mudanças tecnológicas e à interação dinâmica entre elas, não precisando, necessariamente, serem invenções primárias. Já para Rogers e Shoemaker (1971 apud TIGRE, 2006), a inovação é definida como "uma ideia, uma prática ou um objeto percebido como novo pelo indivíduo", não 
associando a inovação obrigatoriamente ao conhecimento científico.

Dacorso et al. (2007) entendem que o conceito moderno de inovação nasceu com Schumpeter (1934), segundo o qual produzir é uma combinação de forças e materiais disponíveis. A inovação é, pois, o resultado da produção de uma combinação nova entre esses elementos, um conjunto de possibilidades - seja no âmbito da gestão das empresas privadas ou no das empresas públicas - conducente à produção da inovação. Importa, no entanto, destacar que não existe uma definição única para contextualizar o processo de inovação. Observam-se, na literatura científica, diversos conteúdos semânticos, com cada pesquisador a definir inovação com base nas suas próprias perspectivas, posicionamentos científicos e contextos de aplicação (RAMOS, 2015).

\subsubsection{Tipologias}

Quanto à inovação, sua tipologia é considerada, segundo Sarkar (2010), sob duas perspectivas: a Macro e a Micro. Na primeira, a inovação é vista como algo novo para o mundo, para a indústria e para o mercado. Na segunda, ela é vista como novidade para a empresa e o consumidor. Destaque-se, ainda, a variedade de tipos e de classificações para o processo de inovação, aspecto que não será tratado no presente estudo, que aborda apenas as inovações tecnológicas consideradas radicais e incrementais, em que as incrementais ou contínuas representam pequenas alterações nas características do objeto foco da mudança, referindo-se a melhorias contínuas introduzidas em algo já existente, e caracterizadas pelo efeito cumulativo de fundamental importância para o progresso tecnológico. Ocorrem de forma contínua e não derivam necessariamente de atividades de P\&D. São resultantes mais do processo de aprendizagem e da inovação em nível elementar e gradual das mudanças tecnológicas, abrangendo melhorias feitas no design ou na qualidade dos produtos (RAMOS, 2015; FREEMAN; SOETE, 2008; TIGRE, 2006; ABERNATHY; CLARK, 1985). A inovação radical (ou descontínua) apoia-se em um novo paradigma, em novos produtos, em novas $\mathrm{P} \& \mathrm{D}$ e em desenvolvimentos que dão lugar à descoberta de novas aplicações. Representa a transição que rompeu trajetórias existentes, inaugurando uma nova rota tecnológica (RAMOS, 2015; FREEMAN; 
SOETE, 2008; TIGRE, 2006; ABERNATHY; CLARK, 1985). Refere-se a inovações que tornam obsoletas as anteriormente existentes, consistindo, portanto, nas inovações vinculadas à abordagem da "destruição criativa" referida por Schumpeter (1934).

A distinção entre inovações radicais e incrementais é mais fácil de intuir do que de definir ou medir. Como a diferença entre radical e incremental é interpretada, muitas vezes, pelo grau percebido de novos conhecimentos incorporados ou desenvolvidos, os gestores tendem a divergir no seu julgamento, principalmente por causa do seu nível de familiaridade e/ou de experiência com a inovação. Sendo assim, a colocação de uma inovação em um continuum depende das percepções de quem está familiarizado com o grau de partida da inovação e do estado de conhecimento prévio para a sua introdução.

\subsection{A INOVAÇÃO NO AGRONEGÓCIO}

A inovação no agronegócio no Brasil, segundo Crestana e Silva (2006, p. 9), sofre um processo contraditório e heterogêneo, enquanto parte considerável da produção mundial da terra é proveniente de agricultores familiares que têm pouco, ou nenhum, grau de inovação nos seus processos, mas seguem modelos passados por gerações e seguem padrões totalmente empíricos. Por outro lado, ainda segundo os autores, há no território nacional sistemas de agronegócios que funcionam como verdadeiros centros de tecnologia, com inovações que vão desde os processos, as ferramentas e maquinários utilizados até o próprio insumo, alterado geneticamente a fim de se aumentar a produtividade.

Essa disparidade, segundo Mendes (2009), é devido à distância observada entre os setores produtores de inteligência científica e os produtores. Mais especificamente, a relação pouco eficiente entre os atores do setor público EMBRAPA, universidades etc. - e os produtores é o que dificulta poderem chegar essas novas tecnologias a beneficiar o agronegócio como um todo. Contudo, para o autor, há iniciativas desses setores em diminuir essa distância, visando a superar as dificuldades inerentes ao sistema agrícola brasileiro e, dessa forma, possibilitar um uso mais eficiente da terra e dos meios de produção. Nesse sentido, é preciso ter-se em mente o destaque de Morgan (1997) ao definir inovação em um sentido 
muito mais amplo do que apenas tecnológico, olhando, sim, para tudo o que se encontra envolvido na produção, incluindo a inovação na gestão e nos processos. Essa faceta da inovação se faz presente no agronegócio e é de extrema importância que seja levada em consideração, quando se abordam os processos de inovação e a sua influência na construção de vantagens competitivas.

Jank e Nassar (2000) ressaltam o papel preponderante do processo de inovação, uma vez que influencia a competitividade dos sistemas agroindustriais, ante o processo de globalização e de integração econômica do mundo, principalmente quando esse segmento da economia brasileira responde por grande parte da receita proveniente da venda para o mercado externo. E, nesse mercado, a capacidade produtiva, proveniente da implementação de inovação e da capacidade de inovar e de coordenar/assimilar inovações, pode ser transformada em vantagens competitivas, condição imprescindível para o sucesso desse setor em um mercado tão concorrido quanto o internacional.

O investimento em Pesquisa e Desenvolvimento (P\&D) ainda é muito concentrado no setor público, como destaca Wilkinson (2000) e Lemos Moro (2000). Segundo eles, mais de $90 \%$ dos investimentos nesse setor vêm de apoios governamentais. Para Cassiolato e Lastres (2003), isso se deve ao fato de que o setor privado acredita que o investimento estrangeiro, por si só, é capaz de modernizar os sistemas de produção agropecuários brasileiros. Porém os autores destacam que inovação e tecnologia são meios de conseguir vantagem competitiva localizada. $\mathrm{E}$ a única forma de o Brasil conseguir a eficiência dinâmica dos setores de produção reside na capacidade de o país poder desenvolver e implementar inovações.

\subsection{O MODELO INTEGRADO DE INOVAÇÃO}

$\mathrm{Na}$ literatura sobre inovação e suas relações com o ambiente empresarial, encontram-se diversas abordagens e uma vasta classificação das tipologias para categorizar o processo de inovação. Dessa forma, impõe-se a necessidade de fazer-se a ligação que vá além da relação entre a inovação e o mercado.

Para Sarkar (2010), o interesse na abordagem integrada vem do fato de a maioria dos modelos em gestão não abordarem relações comportamentais entre as 
variáveis explicativas do fenômeno da inovação e da ação empreendedora. Segundo o autor, o modelo desempenha uma função de diagnóstico, identificando, para isso, o posicionamento do produto em termos da pressão competitiva e da diferenciação/ inovação e, a partir desse posicionamento, explicar a razão dos resultados da empresa.

O enquadramento do modelo integrado de inovação reside no mapeamento da empresa, segundo Sarkar (2010), em um quadro de quatro espaços definidos pelo conjunto das dimensões: i) Quadrante - Archetype Space $\left(\mathrm{Q}_{\mathrm{I}}\right)$ - representa a relação entre o ambiente externo e a orientação estratégica. $O$ ambiente externo é representado pelo grau de pressão competitiva (eixo horizontal) e pelo grau de diferenciação/inovação do produto (eixo vertical). Quanto mais posicionado um produto ou a empresa para a direita no eixo horizontal, maior é a pressão da concorrência, enquanto que, quanto mais para cima no eixo vertical, mais inovador(a); ii) Quadrante - Strategy Space $\left(\mathrm{Q}_{\mathrm{II}}\right)$ - relaciona a inovação do produto com o seu nível de resultados: quotas de mercado, margens ou lucros, ou seja, maiores níveis de diferenciação/inovação conduzirão sempre a melhores lucros; iii) Quadrante - Outcome Space $\left(\mathrm{Q}_{\mathrm{III}}\right)$ - para manter a simplicidade do modelo, utilizase uma bissetriz como artifício (espelho), possibilitando que a variável de resultados passe para o IV Quadrante, relação entre a quota de mercado e o lucro; e iv) Quadrante - Market Space $\left(Q_{\mathrm{IV}}\right)$ - relação entre o ambiente externo e os resultados para uma dada orientação estratégica.

\section{ASPECTOS METODOLÓGICOS}

No estudo, fez-se opção por um método qualitativo-exploratório, utilizando-se como referência o modelo de inovação desenvolvido por Sarkar (2010). A pesquisa teve, como base empírica, os dados recolhidos durante o seu desenvolvimento, buscando estudar as dinâmicas de inovação em um conjunto de empresas exportadoras de manga da RIDE, localizada no polo emergente do Vale do São Francisco.

Nesse caso, em específico, o estudo buscou posicionar as empresas 
exportadoras de manga da RIDE, analisando de forma especial os fatores que contribuíram para esse posicionamento. Para tanto, fez a leitura somente do Quadrante (QI) - Espaço dos Arquétipos.

Ressalte-se que, dependente da combinação entre pressão competitiva e o grau de inovação no Quadrante (QI), foi possível obter o agrupamento das empresas em quatro arquétipos de mercado: i) o arquétipo lobo: espaço que se caracteriza pela existência de poucas empresas oferecendo produtos/serviços muito diferenciados; ii) o arquétipo raposa: espaço que se caracteriza pela existência de um grande número de empresas operando em uma atmosfera competitiva; iii) o arquétipo urso: espaço que se caracteriza pela existência de poucas empresas e baixa diferenciação/inovação de produtos/serviços; e iv) o arquétipo ovelha: espaço que se caracteriza pela existência de um grande número de empresas que oferecem produtos/serviços semelhantes ou homogêneos.

\subsection{DELIMITAÇÃO DA AMOSTRA}

O trabalho centra-se em estudo de caso múltiplo, realizado com seis empresas de pequeno, médio e grande porte, todas sediadas na RIDE, que representam, em termos de área cultivada, cerca de $14 \%$ do total dos 17.472 hectares implantados, conforme dados do MIDIC/DEAEX (2016). Para a seleção da amostra, foram pesquisadas empresas produtoras e exportadoras de manga sediadas na RIDE. Tratou-se, portanto, de uma amostra não probabilística e não aleatória. Na coleta de dados, foi utilizado um questionário (tipo estruturado), aplicado aos principais gestores das empresas, e a análise de documentos sobre a produção de manga (sites, artigos, dissertações) e as empresas (entrevistas e publicações). Ressalte-se que os dados foram recolhidos durante os meses de julho e agosto de 2016.

\subsection{RECOLHA E TRATAMENTO DOS DADOS}

O inquérito aplicado encontra-se dividido em três partes, sendo a primeira delas sobre a capacidade de inovação (onde se buscou trabalhar com um conjunto de variáveis do tipo nominal e ordinal). A segunda parte é constituída de quatro blocos de respostas, em uma escala de medida do tipo métrica (com uma escala 
de variação de 1 a 7 - variáveis do tipo escalar), com vista a medir um conjunto de variáveis (mercado, produto, processo de produção e resultados). No primeiro bloco, 14 perguntas relacionadas com o mercado; no segundo, 14 perguntas sobre o produto; no terceiro, 10 perguntas acerca do processo de produção; e o quarto, 05 perguntas sobre os resultados. Para caracterizar o conjunto de dados concernentes às dimensões propostas, foram calculados os valores referentes à média e ao desvio padrão. A terceira e última parte buscou levantar dados sobre o perfil sociodemográfico dos gestores (das empresas envolvidas na pesquisa) e informações sobre a organização (número de funcionários, ano de fundação etc.), visando a categorizar as empresas envolvidas no estudo.

O questionário elaborado teve como referência a abordagem teórica aqui desenvolvida e os pressupostos estabelecidos pelo Modelo Integrado de Inovação. Trata-se de uma análise mais holística sobre o processo de inovação, derivada do fato de a maior parte dos modelos em gestão não abordarem as relações comportamentais entre um conjunto de variáveis. Ressalte-se que esse instrumento de coleta de dados já havia sido validado, anteriormente, por Sarkar (2005), ao conceber o Modelo Integrado de Inovação, e em dois outros momentos por Carvalho e Sarkar (2010), no setor de turismo, e por Ramos et al. (2014), quando estudaram as estratégias de inovação no agronegócio, especificamente em uma empresa vitivinícola do Vale do São Francisco. Segundo Sarkar (2010), o ponto alto da abordagem integrada da inovação é, na verdade, a simplicidade, embora seja verdade que possa se tornar demasiadamente limitada para explicar as relações mais complexas entre várias variáveis estudadas.

\section{ANÁLISE E DISCUSSÃO DOS RESULTADOS}

\subsection{ECOSSISTEMA DO AGRONEGÓCIO DA MANGA}

\subsubsection{Panorama Mundial}

Um dos seus pontos fortes é o seu total aproveitamento. Segundo o SEBRAE (2016), a manga é comercializada geralmente na forma fresca, mas também 
é encontrada em forma de compota, suco integral e polpa congelada. A polpa é utilizada na produção de doces, geléias, sucos e néctares, além de ser adicionada a sorvetes, misturas de sucos, licores e outros produtos. Suas folhas e tronco são aproveitados nas indústrias farmacêutica e madeireira.

Segundo a FAO (2016), o Brasil é o sétimo maior produtor de manga, atrás apenas de países asiáticos, como a Índia (produzindo aproximadamente 20 milhões de toneladas) e a China - as quais, juntas, representam cerca de um terço da população mundial -, Tailândia, Indonésia e Paquistão. Além desses, também o México figura entre os maiores produtores. A manga brasileira está valorizada e a perspectiva é de que sua demanda mundial aumente cada vez mais, impulsionada pela recuperação da economia mundial e das ações de marketing nos Estados Unidos realizadas pelo National Mango Board (LIMA, 2015). Entretanto é necessário que os produtores invistam cada vez mais em técnicas para maximizar sua eficiência produtiva, com o objetivo de se manterem competitivos em relação ao Peru e Equador, países vizinhos que possuem custos de produção menores, mas, em contrapartida, volumes de produção baixos (LIMA, 2015).



Gráfico 1. Exportação de Manga Mundial em toneladas 2005-2013

Fonte: Elaboração própria a partir de dados da FAO e MIDIC/DEAEX (2016).

Em termos de exportação, segundo a FAO (2016), o Brasil é um dos 
principais exportadores de manga. Analisando o Gráfico 1, é possível destacar o crescimento da Tailândia como exportador. Em 2005, seu volume exportado foi insignificante em relação aos grandes exportadores. Contudo, em apenas oito anos depois, sua exportação atingiu volume maior que o do Brasil, consolidando o país como um dos principais exportadores mundiais. Outro fator importante para Branco (2014), é o crescimento do Peru nas exportações de manga. Vem ganhando força, principalmente no mercado norte-americano, em que já ganhou parte da demanda atendida pelo Vale do São Francisco, concorrendo diretamente com os produtores brasileiros. Grande parte do mercado norte-americano é conquistado pelos mexicanos, com cerca de 55\%, enquanto o Brasil atinge apenas 10\% do mercado (ARAUJO, 2015). Para Araújo (2015), o Brasil é responsável por um total de 20\% da manga comercializada internacionalmente, com os Estados Unidos na posição de maior importador desse produto. Juntamente com Japão, Alemanha e Holanda, respondem os três países por quase um quinto das importações mundiais de manga.

\subsubsection{Panorama Nacional}

Algumas regiões do Brasil sobressaem na produção de manga. De acordo com o Instituto Brasileiro de Geografia e Estatística (IBGE), em 2014, o Nordeste foi responsável por $69 \%$ da produção de manga e a região Sudeste, por 30\%, correspondendo somadas a, praticamente, toda a produção brasileira da fruta. Segundo o Hortifruti Brasil (2015), os principais municípios produtores de manga são: Petrolina (PE), Juazeiro (BA), Livramento de Nossa Senhora (BA), Monte Alto (SP), Taquaritinga (SP), Andradina (SP), Jaíba (MG) e Janaúba (MG), concentrados nas regiões Nordeste e Sudeste. No Vale do São Francisco, região na fronteira entre Bahia e Pernambuco, concentra-se a maior produção de manga para exportação, representando 84\% das exportações brasileiras de manga no ano de 2015 (ANUÁRIO BRASILEIRO DA FRUTICULTURA, 2016). Os maiores clientes são a União Europeia, Estados Unidos e Canadá, como mostra o Gráfico 2. 




Gráfico 2. Principais Destinos da Manga Exportada 2015

Fonte: Elaboração própria a partir de dados do MIDIC/AliceWeb (2016).

A produtividade do cultivo de manga tem aumentado, segundo Rocha (2016), influenciada principalmente pelo surgimento de novos insumos, técnicas de indução de florada e manejo adequado. Os maiores desafios enfrentados pelo Brasil são a sua estrutura limitada de exportação e a qualidade da fruta, que não é recebida em todos os países. Por outro lado, o preço competitivo é uma de suas vantagens (ROCHA, 2016). A maior dificuldade do Brasil em competir com seus principais concorrentes de exportação mundial - Índia, México, Peru e Equador - diz respeito aos seus custos variáveis de produção mais altos, que o levam a comercializar suas frutas a preços médios mais elevados. Para ampliar esta desvantagem, há o fato de seus concorrentes possuírem acordos comerciais com os principais importadores de commodities, fazendo com que as tarifas comerciais diminuam (BRANCO, 2014). Devido a isso, os produtores assumem a estratégia de esperar o período de venda dos principais exportadores, para então entrar no mercado, aproveitando a entressafra da maioria dos países (BRANCO, 2014).

\subsubsection{Panorama Regional}

A Região Integrada de Desenvolvimento Econômico Petrolina (PE) e Juazeiro (BA) - RIDE é composta por municípios de dois Estados: o de Pernambuco, com os municípios de Lagoa Grande, Orocó, Petrolina e Santa Maria da Boa Vista; e o da Bahia, com Casa Nova, Curaçá, Juazeiro e Sobradinho. A sua dinâmica econômica é promovida pela fruticultura irrigada, devido à posição estratégica da 
região, banhada pelas águas do rio São Francisco, e também por conter solos ricos com grande potencial de desenvolvimento da agricultura irrigada, tanto na margem esquerda, onde predominam os de textura arenosa média, como na margem direita, com solos de classe média a muito argilosos (RIBEIRO, 2014).

O Gráfico 3 representa a participação da RIDE na produção de manga, ressaltando e afirmando a importância da região como principal polo frutícola do país (RIBEIRO, 2014). Segundo Ribeiro (2014), a maior parte da produção está concentrada nos estabelecimentos dos médios e grandes produtores instalados nos projetos públicos ou nas propriedades dos polos frutícolas situados na região. A região está consolidada no cultivo da manga, porém ainda sofre com alguns problemas, como elevadas temperaturas, que, segundo Hortifruti Brasil (2015), prejudicam o desenvolvimento das flores, com redução, por exemplo, da oferta em cerca de $30 \%$, tal como observado no ano de 2013. Outro fator ligado à produção e à qualidade da fruta para a exportação é o da mosca da fruta, para o qual são necessários o controle químico, técnicas de manejo da produção, fiscalização sanitária e criação de fundos para financiar as ações de controle da praga, a fim de oferecer um produto com as especificações exigidas pelos principais clientes (HORTIFRUTI BRASIL, 2014). Esses problemas são refletidos na capacidade de produção da região. Outra observação importante é a presença da RIDE mundialmente, devido à sua grande participação nas exportações brasileiras, com média acima de $65 \%$, e por possuir números maiores que importantes países. O Gráfico 3 detalha melhor a participação da RIDE na exportação brasileira de mangas durante o período entre 2005 e 2013.

\section{Part RIDE/Brasil}

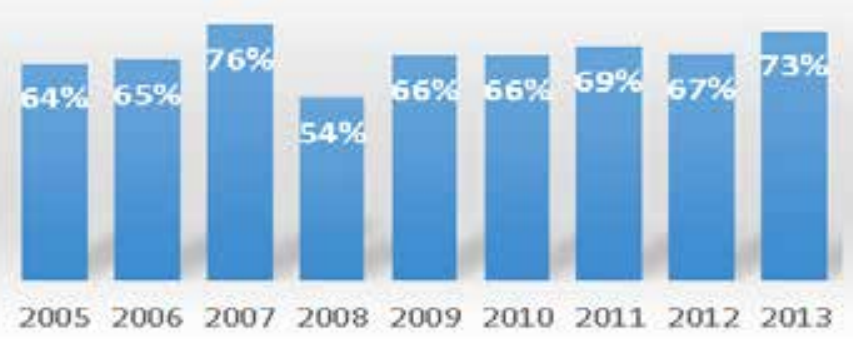

Gráfico 3. Participação da RIDE nas exportações brasileiras de manga Fonte: Elaboração própria a partir de dados do MIDIC/DEAEX (2016). 
Segundo Vetucci et al. (2016), a manga se distingue comercialmente em duas categorias, as oblongas e as vermelhas. As oblongas são encontradas principalmente na Ásia, tornando-se matéria-prima de produtos processados com consumo internacional. As mangas vermelhas são responsáveis pela maior parte do mercado internacional, com destaque, dentre elas, para a Palmer, Tommy Atkins, Keitt e Kent. Concentrando-se a oferta da fruta, no cenário mundial, nos meses entre abril e setembro, quando os preços de mercado são mais baixos, possibilita-se uma maior cotação nos meses de outubro a março devido à baixa oferta.

\subsubsection{Análise e Discussão dos Dados}

Nesta etapa de trabalho, foram realizadas a análise e discussão dos dados recolhidos relativamente às dinâmicas de inovação nas empresas exportadoras de frutas, inseridas na RIDE e selecionadas para a condução desta pesquisa. Inicialmente, buscou-se apresentar os dados referentes à primeira e à terceira parte do questionário (Caracterização da empresa, perfil sociodemográfico dos gestores e capacidade de inovação). O perfil sociodemográfico dos gestores envolvidos na pesquisa é marcado pelas seguintes características (tendo como referência o ano de 2016): i) a maioria dos gestores tem mais de 50 anos; ii) todos são do gênero masculino; iii) ocupam o cargo de Diretor Executivo; e iv) quanto à escolaridade, todos são detentores de curso superior completo, com a metade deles possuindo especialização.

No Quadro 1 estão sintetizados os principais indicadores da capacidade de inovação das empresas, tendo por base as variáveis:

Quadro 1. Indicadores da capacidade de inovação

\begin{tabular}{|l|l|}
\hline \multicolumn{1}{|c|}{ Variáveis } & \multicolumn{1}{c|}{ Descrição } \\
\hline Realiza atividades de P\&D & $\begin{array}{l}\text { A maioria das empresas informou que realizam atividades de } \\
\text { P\&D. }\end{array}$ \\
\hline $\begin{array}{l}\text { Parcerias com outras } \\
\text { entidades em atividade P\&D }\end{array}$ & $\begin{array}{l}\text { As parcerias realizadas com outras entidades, em atividade de } \\
\text { P\&D, são instituídas com fornecedores e laboratórios comerciais } \\
\text { ou empresas de P\&D. }\end{array}$ \\
\hline $\begin{array}{l}\text { \% de funcionários envolvidos } \\
\text { em P\&D }\end{array}$ & $\begin{array}{l}\text { 82\% das empresas afirmaram que menos de 10\% dos seus } \\
\text { funcionários se encontram envolvidos com as atividades de } \\
\text { P\&D. }\end{array}$ \\
\hline
\end{tabular}




\begin{tabular}{|l|l|}
\hline \multicolumn{1}{|c|}{ Variáveis } & \multicolumn{1}{c|}{ Descrição } \\
\hline $\begin{array}{l}\text { Introduziu no mercado algum } \\
\text { produto/serviço inovador }\end{array}$ & $\begin{array}{l}\text { Metade das empresas tem buscado desenvolver/adotar ações } \\
\text { estratégicas de inovação no produto e serviços. }\end{array}$ \\
\hline $\begin{array}{l}\text { Introduziu inovação no } \\
\text { processo }\end{array}$ & $\begin{array}{l}\text { As empresas na sua totalidade introduziram inovações nos seus } \\
\text { processos produtivos. }\end{array}$ \\
\hline $\begin{array}{l}\text { Introduziu inovação } \\
\text { administrativa }\end{array}$ & $\begin{array}{l}\text { A maioria das empresas desenvolveu ações estratégicas de } \\
\text { inovação relacionadas com seus processos de gestão. }\end{array}$ \\
\hline
\end{tabular}

Fonte: Elaboração própria a partir de dados colhidos via questionário.

As principais ações estratégicas de inovação implementadas pelas empresas exportadoras, tendo por base os pressupostos do Modelo Integrado de Inovação, encontram-se resumidas na Tabela 1 . O posicionamento das empresas no Modelo Integrado de Inovação segue os dados fornecidos pela Tabela 1.

Tabela 1. Caracterização das dimensões

\begin{tabular}{c|c|c|c|c|c|c}
\hline \multirow{2}{*}{ Empresas } & \multicolumn{2}{|c|}{ Nosso Mercado } & \multicolumn{2}{c|}{ Nosso Produto } & \multicolumn{2}{c}{ Nosso Processo } \\
\cline { 2 - 7 } & Média & DP & Média & DP & Média & DP \\
\hline \multirow{2}{*}{ A } & 5,57 & 1,22 & 3,50 & 2,02 & 4,80 & 1,39 \\
B & 4,79 & 1,31 & 5,21 & 0,69 & 6,60 & 0,84 \\
C & 5,50 & 2,17 & 3,93 & 2,20 & 6,10 & 0,87 \\
D & 4,57 & 2,02 & 4,00 & 1,79 & 2,60 & 2,22 \\
E & 5,43 & 1,65 & 5,50 & 1,99 & 6,20 & 1,31 \\
F & 5,18 & 0,99 & 4,64 & 1,40 & 5,05 & 0,89 \\
\hline
\end{tabular}

Fonte: Elaborado pelos autores com apoio nos dados obtidos via questionário.

Os dados estão relacionados com a segunda parte do questionário. Trata-se da avaliação das quatro dimensões propostas para a análise no Modelo Integrado de Inovação dos gestores. A análise interna das dimensões - Nosso Mercado, Nosso Produto, Processo de Produção e Resultados - possibilitou identificar o posicionamento de cada uma das empresas estudadas. Destaque-se que as análises desenvolvidas estão diretamente relacionadas com as inovações tecnológicas (inovações no produto e no processo de produção), conforme já mencionado no referencial teórico do trabalho. 
A Figura 1 apresenta o mapeamento interno do produto, mediante as estratégias de inovação das empresas, o que possibilitou o posicionamento de cada uma delas no espaço integrado de inovação.

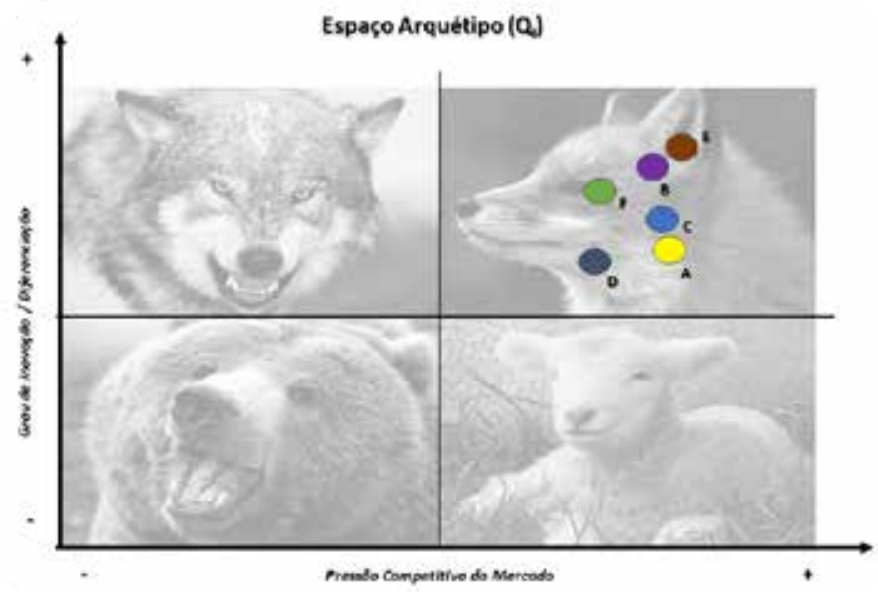

Figura 1. Espaço Arquétipo do Nosso Produto

Fonte: Elaborado pelos autores com apoio nos dados obtidos via questionário.

A Figura 1 possibilita, ainda, duas análises: a primeira diz respeito ao locus/ posicionamento da empresa frente à pressão competitiva do mercado. Pelo que se pode observar, todas as empresas estão posicionadas no arquétipo "raposa", caracterizado por uma atmosfera competitiva decorrente do grande número de empresas. Observa-se um cluster de empresas com estratégias de inovação semelhantes - caso das empresas A, B, C, D e F - e um caso específico, como o da empresa $\mathrm{E}$, que, apesar de estar em um ambiente competitivo, apresenta grau elevado de inovação/diferenciação. 


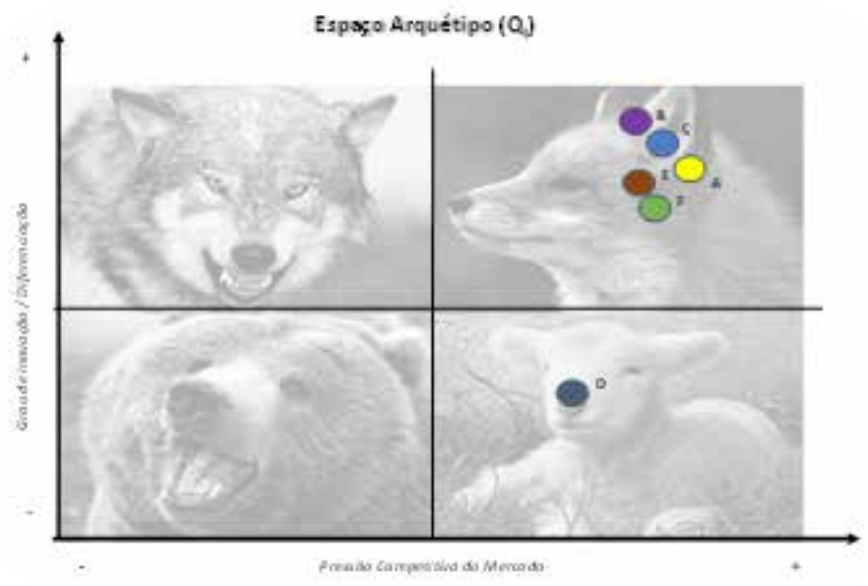

Figura 2. Espaço Arquétipo do Nosso Processo

Fonte: Elaborado pelos autores com apoio nos dados obtidos via questionário.

Quanto ao mapeamento interno do processo de produção, a Figura 2 possibilitou um novo posicionamento de cada uma das empresas no espaço integrado de inovação. Constata-se, nessa nova análise, uma mudança no posicionamento das empresas, reforçando um novo posicionamento estratégico de inovação, além de um novo cluster (A, B, C, E e F), onde apenas a empresa D posicionou-se em outro arquétipo, o da "ovelha", o que, segundo Sarkar (2010), aponta para um mercado de forte concorrência, homogeneidade de produtos e de baixo grau de inovação.

\section{CONSIDERAÇÕES FINAIS}

O diagnóstico realizado deixa claro que, nos dois mapeamentos, a maioria das empresas está inserida no arquétipo "raposa", caracterizado por um ambiente de forte pressão competitiva e elevado grau de inovação/diferenciação, seja no produto ou no processo de produção, fato esse corroborado nas considerações de Sarkar (2010) acerca de seu próprio modelo, ao afirmar que, no mundo dos negócios, há inúmeros exemplos de empresas que poderiam ser caracterizadas de "raposas", tendo em vista os seus esforços em criar nichos de mercado por meio da inovação de produto e/ou no processo de produção. Todavia essas inovações, muitas vezes 
adotadas, são facilmente imitadas pela concorrência, caracterizando-se, assim, como contributos de curto prazo, já que esses tipos de inovações têm baixo grau de proteção, o que torna imperativo as constantes ações das empresas na busca da diferenciação em relação aos seus concorrentes.

Sobre as decisões estratégicas de inovação, particularmente as associadas à capacidade de inovação, faz-se necessário destacar que são atividades de P\&D limitadas e, na maioria das vezes, de natureza incremental. Além disto, são dependentes de avanços tecnológicos gerados em outros setores, fator esse que exige uma mudança de postura das empresas frente às atividades de P\&D. Os gestores das empresas exportadoras de manga da RIDE revelaram que desenvolvem esforços contínuos em atividade de $\mathrm{P} \& \mathrm{D}$, em parceria com fornecedores e laboratórios comerciais ou empresas de P\&D. No entanto a pífia participação (menos de $10 \%$ ) dos seus recursos humanos, ainda assim pode contribuir para níveis de acumulação de novos conhecimentos e de comprometimento dos demais profissionais atuantes nessas organizações.

Os esforços organizacionais para introduzir inovações estão, predominantemente, focados em melhorias no processo de produção, quando comparados à introdução de novos produtos, significativamente melhorados, no mercado. Essa mesma evidência já havia sido constatada em estudos realizados por Ramos, Oliveira e Clementino (2014), ao destacarem que as ações estratégicas de inovação direcionadas para o processo de produção (vitícola e vinícola) possibilitaram a diferenciação do produto, com a melhoria da qualidade do vinho, atingindo níveis de excelência e de exigência de consumidores de mercados tradicionalmente produtores de vinho. Por outro lado, observou-se que a maioria das empresas desenvolveu ações estratégicas de inovação de caráter administrativo em seus empreendimentos. Entre essas ações, estão a flexibilização da estrutura hierárquica das empresas, a adoção de tecnologias gerenciais, novos mecanismos de controle e maior participação no processo decisório, como as ações emergentes identificadas como melhorias e adequações realizadas no âmbito do modelo de negócio e na gestão dos empreendimentos.

A análise dos dados obtidos com as dimensões "Nosso Mercado", "Nosso Produto" e "Resultados", excluindo-se, em um primeiro momento, a dimensão 
"Nosso Processo de Produção", possibilitou posicionar todas as empresas exportadoras de manga da RIDE, como dito anteriormente, no Espaço Arquétipos "Raposa", exatamente pela adoção de mecanismos que possibilitaram a diferenciação dos produtos/serviços, estruturas de custos mais enxutas e, consequentemente, a diversificação no leque de produtos. Por outro lado, ao excluir a dimensão "Nosso Produto" e incluir a dimensão "Nosso Processo de Produção", observou-se a manutenção do Espaço Arquétipos "Raposa" para a maioria das empresas, tendo em vista as ações estratégicas de inovação centradas na adoção de variedades focadas no mercado e por mudanças significativas nos processos de plantio e condução dos pomares. Ressalte-se, porém, que não basta adicionar acessórios ao processo produtivo. Fazem-se necessárias, igualmente, ações agressivas de melhoria nos processos de produção, bem como na melhoria da qualidade dos produtos e/ou serviços a serem oferecidos. Por fim, evidencie-se o posicionamento da "Empresa D", que se deslocou para baixo passando a ocupar o "Espaço Arquétipo Ovelha". Nesse quadrante, a empresa deve ter maior atenção no controle dos custos e na produtividade, como mecanismos de sobrevivência, assim como deve buscar a diferenciação dos seus processos de produção por meio da adoção de inovação.

As inovações ocorreram em um continuum e vão desde a adoção de novos produtos/serviços a melhorias significativas nos processos de produção, caracterizadas por estratégias de inovaçooes tecnológicas, de caráter incremental, além de inovações administrativas, nomeadamente, no nível do modelo de negócio, fatores esses que têm contribuído para a manutenção e a sustentabilidade das vantagens competitivas das empresas, ante à intensificação da competitividade nos mercados nacional e internacional. Por fim, seja esclarecido que o presente estudo se limitou a diagnosticar, no conjunto de empresas exportadoras de manga da RIDE, o seu posicionamento no Espaço Arquétipos (quadrante I), do Modelo Integrado de Inovação de Sarkar. Portanto os resultados ora apresentados não permitem generalizações de seus resultados, dada a restrição de sua amplitude, embora o Modelo Integrado permitisse o mapeamento (diagnóstico da inovação) no espaço integrado de forma mais abrangente e holística, como, por exemplo: Qual a perspectiva do cliente em relação à inovação do produto/serviço? Quanto é diferente na perspectiva da empresa? Os resultados de mercado alcançados pela empresa diferem dos seus rivais mais próximos? Buscar-se-á responder a tais questões em pesquisas futuras. 


\section{REFERÊNCIAS}

ABERNETHY, W.; CLARK, K. Innovation: Mapping the winds of creative destruction. Research Policy, 14, p. 03-22, 1985.

ANUÁRIO BRASILEIRO DA FRUTICULTURA 2016. Santa Cruz do Sul: Gazeta Santa Cruz, 2016.

ARAUJO, W. Matriz de análise política aplicada à cadeia produtiva da manga no município de Petrolina, Pernambuco. 2015. 102f. Dissertação (Mestrado em Economia) - Universidade Federal do Ceará, Fortaleza.

BRANCO, D. Impactos da ferrovia Transnordestina na exportação de manga e uva do Vale Submédio São Francisco. 2014. 59f. Dissertação (Mestrado em Economia) - Universidade Federal de Pernambuco, Caruaru.

CASSIOLATO, J. E.; MACIEL, M. L. Pequena empresa: cooperação e desenvolvimento local. Rio de Janeiro: Relume Dumará, 2003.

CRESTANA, S.; SILVA, R. C. Uma possível história da inovação e gestão do agronegócio no Brasil. In: ZUIN, L. F. S. et al. Agronegócio: gestão e inovação. São Paulo: Saraiva, 2006.

DACORSO, A. L. R.; LEITE, K. C.; MOLINA-PALMA, M. A. Inovação e competitividade: um estudo sobre a capacidade de inovar do pequeno produtor de rosas de Barbacena (MG). Estud. Soc. Agric., Rio de Janeiro, v. 12, n. 1, 2007.

FAO. Statistical Databases. Disponível em: < http://faostat.fao.org/>. Acesso em: 01 jul. 2016.

FREEMAN, C.; SOETE, L. A economia da inovação industrial. São Paulo: Ed. UNICAMP, 2008.

HORTIFRUTI BRASIL. Agentes do bem: biológicos entram em ação. Manga. Cepea Esalq-USP, v. 13, n. 136, 2014. 
HORTIFRUTI BRASIL. Anuário 2014 - 2015. Manga. Cepea Esalq-USP, v. 13, n. 141, 2015.

HORTIFRUTI BRASIL. Banco de Dados. Preços Médios dos Hortifrutícolas. Cepea Esalq-USP. Disponível em: < http://www.hfbrasil.org.br/br/banco-de-dados-precosmedios-dos-hortifruticolas.aspx > . Acesso em: 03 jul. 2016.

INSTITUTO BRASILEIRO DE GEOGRAFIA E ESTATÍSTICA. Séries Históricas e Estatísticas. Produção Agrícola Municipal (PAM). Lavoura permanente - quantidade produzida. Disponível em: < http://seriesestatisticas.ibge.gov.br/series.aspx?no=1 $\& o p=0 \& v \operatorname{codigo}=\mathrm{PA}$ \& $\mathrm{t}=$ lavoura-permanente-quantidade-produzida $>. \quad$ Acesso em: 08 jul. 2016.

JANK, M. S.; NASSAR, A. M. Competitividade e globalização. In: ZYLBERSZTAJN, D.; NEVES, M. F. (Coord.). Economia e gestão dos negócios agroalimentares. São Paulo: Pioneira, 2000.

LEMOS, M. B.; MORO, S. O contexto macro da dinâmica de inovação do sistema agroalimentar do Mercosul ampliado. Montevideo: Procisur/BID. 2000. 47p. (Série Documentos $\mathrm{n}^{0} 1$ ).

LIMA, J. Evolução das exportações de Manga e Uva produzidas no Submédio do Vale do São Francisco no período de 2010-2014. Embrapa Semiárido, Petrolina, 2015.

LUSTOSA, M. C. J. Inovação e tecnologia para uma economia verde: questões fundamentais. Política Ambiental: Economia Verde: Desafios e Oportunidades, $\mathrm{n}^{\circ} 8$, Belo Horizonte, Junho de 2011.

MENDES, P. J. V. Organização da P\&D agrícola no Brasil: evolução, experiências e perspectivas de um sistema de inovação para a agricultura. 2009. Tese (Doutorado) - Unicamp, Campinas.

MINISTÉRIO DO DESENVOLVIMENTO, INDÚSTRA E COMÉRCIO EXTERIOR - MDIC. Secretaria de Comércio Exterior (SECEX). Dados sobre o comércio exterior 
brasileiro. Disponível em: <http://aliceweb.mdic.gov.br/>. Acesso em: 29 jun. 2016.

MINISTÉRIO DO DESENVOLVIMENTO, INDÚSTRA E COMÉRCIO EXTERIOR - MDIC. Estatísticas de Comercio Exterior - DEAEX. Balança Comercial Brasileira por Município. Disponível em: <http://www.desenvolvimento.gov.br//sitio/sistema/ balanca/>. Acesso em: 21 jun. 2016.

MORGAN, K. The learning region: Institutions, innovation and regional renewal. Regional Studies, v. 31, n. 5, p. 491-503, 1997.

OCDE. Manual de Frascati: Propuesta de Norma Práctica para Encuestas de Investigación y Desarrollo Experimental. Publicação Fundación Española Ciencia y Tecnologia, 2005.

RAMOS, V. D. C. Estratégia empresarial e dinâmicas de inovação: referências para uma gestão estratégica de sucesso no setor vitivinícola brasileiro. 2015. Tese (Doutorado em Gestão) - Universidade de Évora, Portugal.

RIBEIRO, C. Pegada hídrica e água virtual: estudo de caso da manga no Submédio do Vale do São Francisco, Brasil. 2014. 79f. Dissertação (Mestrado em Economia) Universidade Federal da Bahia, Salvador.

ROCHA, A. A Manga. Grupo de Pesquisa e Extensão em Marketing e Gestão. Boletim MarkEsalq em Rede, v. 4, n. 16, 2016.

SAKAR, S. Empreendedorismo e inovação. $2^{\text {a }}$ ed. Lisboa: Escolar, 2010.

SCHUMPETER, J. Strategy, Strategy Making, and Performance - An Empirical Investigation. Management Science, v. 33, n. 2, p. 258-269, 1934.

SERVIÇO BRASILEIRO DE APOIO AS MICRO E PEQUENAS EMPRESAS - SEBRAE. 0 cultivo e o mercado da manga. Disponível em: < http://www.sebrae.com.br/sites/ PortalSebrae/artigos/o-cultivo-e-o-mercado-da-manga,90f5438af1c92410VgnVCM100 000b272010aRCRD > . Acesso em: 06 ago. 2016. 
TIGRE, P. B. Gestão da Inovação: a economia da tecnologia do Brasil. Rio de Janeiro: Elsevier, 2006.

VETUCCI, J.; CALDERAN, A.; BERALDO, P. A Manga. Grupo de Pesquisa e Extensão em Marketing e Gestão. Boletim MarkEsalq em Rede, v. 4, n. 16, 2016.

WILKINSON, J. Demandas tecnológicas, competitividade e inovação no sistema agroalimentar do Mercosul ampliado: Lácteos. Montevideo: Procisur; BID, 2000. 43p. (Série Documentos no 9).

Recebido em: 27 setembro de 2016 Aceito em: 01 de março de 2017 